\title{
Endoscopic Treatment of a Duodenal Duplication Cyst
}

A 23-year-old Caucasian woman underwent investigations for symptoms of epigastric pain and gastroesophageal reflux. She was treated with a proton pump inhibitor for a few months without any improvement in symptoms. Abdominal computed tomography and endoscopic ultrasound examination revealed a paraduodenal cystic lesion on the antimesenteric side of the second part of the duodenum. This lesion was echo-poor, was more than $6 \mathrm{~cm}$ in length, and was composed of multiple layers similar to those of the intestinal wall. The diagnosis was a duodenal duplication. Examination with a side-viewing Olympus TJF-160 duodenoscope revealed a soft and depressible mass (Figure 1). An incision was made with a needle-knife papillotome (Microknife XL; Boston Scientific Microvasive, Spencer, Indiana, USA) on the proximal, dependent portion of the cyst. The cyst was cannulated with a sphincterotome (Cotton Cannulatome II PC Double Lumen; Wilson-Cook Medical, WinstonSalem, North Carolina, USA). The incision was extended until an opening of $1.5 \mathrm{~cm}$ was obtained. One month later, a second endoscopy was performed and the duplication cavity was found to be totally collapsed. The previous incision was now about $2 \mathrm{~cm}$ long and was extended for another $1 \mathrm{~cm}$ (Figure 2 ). One month after discharge, the patient was well and symptom-free.

Duodenal duplication is rarely diagnosed in adults. The most common clinical manifestations are intestinal occlusion, pancreatitis, perforation, or bleeding but symptoms can also be nonspecific, as in our patient [1]. Traditionally, duodenal duplication has been managed surgically and complete resection is the classic treatment. Only a few cases of endoscopic treatment of duodenal duplication have been reported [1-4]. Duodenal duplications are benign lesions, although two cases of malignant transformation have been reported in the literature, probably related to the presence of ectopic tissue inside the cyst, which was not found in

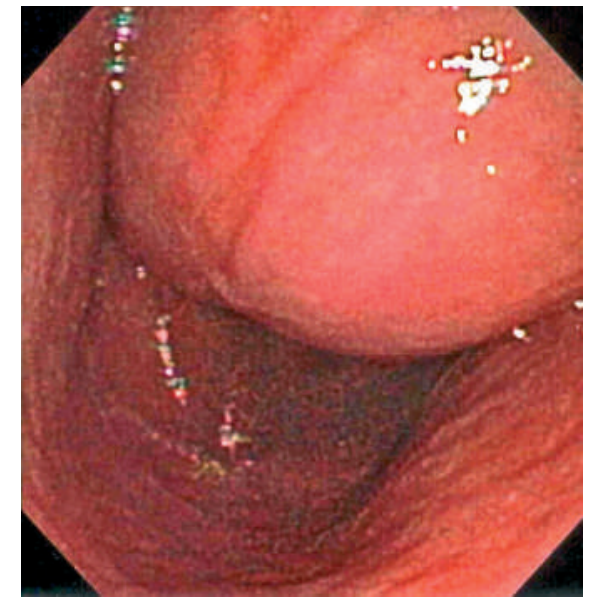

Figure 1 Endoscopic view of a bulging, depressible mass on the antimesenteric side of the second part of the duodenum.

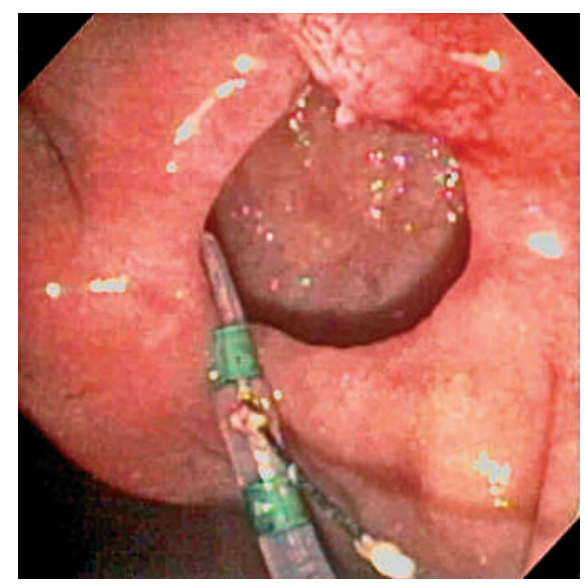

Figure 2 Endoscopic view at the second endoscopy, after extending the incision with a standard sphincterotome. Normal mucosa can be seen inside the duodenal duplication.

our case $[5,6]$. In conclusion, endoscopic treatment of duodenal duplication is an effective procedure which results in rapid relief of symptoms and avoids the morbidity associated with a laparotomy.

\section{F. Vandenbroucke, M. Dagenais,} R. Létourneau, R. Lapointe, A. Roy Hepatobiliary and Pancreatic Surgery Unit, Centre Hospitalier de Montréal Hopital Saint Luc, Montreal, Canada.

\section{References}

${ }^{1}$ Johanson JF, Geenen JE, Hogan WJ, Huibregtse $\mathrm{KH}$. Endoscopic therapy of a duodenal duplication cyst. Gastrointest Endosc 1992; 38: 60-64

2 Wada S, Higashizawa T, Tamada Ket al. Endoscopic partial resection of a duodenal duplication cyst. Endoscopy 2001; 33: $808-810$

${ }^{3}$ Sezgin O, Altiparmak E, Yilmaz Uet al. Endoscopic management of a duodenal duplication cyst associated with biliary obstruction in an adult. J Clin Gastroenterol 2001; 32: 353-355

${ }^{4}$ Al Traif I, Khan MH. Endoscopic drainage of a duodenal duplication cyst. Gastrointest Endosc 1992; 38: 64-65

${ }^{5}$ Falk GL, Young CJ, Parer J. Adenocarcinoma arising in duodenal duplication cyst: a case report. Aust N Z J Surg 1991; 61: $551-553$

${ }^{6}$ Inoue M, Nishimura O, Andachi H, Koga S. Early cancer of duodenal duplication: a case report. Gastroenterol Jpn 1979; 14: $233-237$

\section{Corresponding Author}

\section{A. Roy, M.D.}

Hepatobiliary and Pancreatic Surgery Unit, Centre Hospitalier de Montréal Hopital Saint Luc 1058 Rue Saint Denis

Montreal, Qc H2X3J4

Canada

Fax: $\quad+1-514-412-7380$

E-mail: andre.roy.chum@ssss.gouv.qc.ca 